Article

\title{
Vitamin D Deficiency and Its Associated Factors among Female Migrants in the United Arab Emirates
}

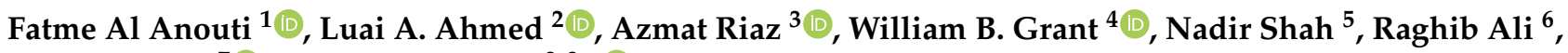 \\ Juma Alkaabi ${ }^{7}$ and Syed M. Shah $2,8, * \mathbb{D}$
}

check for

updates

Citation: Anouti, F.A.; Ahmed, L.A.; Riaz, A.; Grant, W.B.; Shah, N.; Ali, R.; Alkaabi, J.; Shah, S.M. Vitamin D Deficiency and Its Associated Factors among Female Migrants in the United Arab Emirates. Nutrients 2022 14, 1074. https://doi.org/10.3390/ nu14051074

Academic Editor: Connie Weaver

Received: 26 January 2022

Accepted: 22 February 2022

Published: 3 March 2022

Publisher's Note: MDPI stays neutral with regard to jurisdictional claims in published maps and institutional affiliations.

Copyright: (C) 2022 by the authors. Licensee MDPI, Basel, Switzerland. This article is an open access article distributed under the terms and conditions of the Creative Commons Attribution (CC BY) license (https:// creativecommons.org/licenses/by/ $4.0 /)$.
1 Department of Health Sciences, College of Natural and Health Sciences, Zayed University, Abu Dhabi 144534, United Arab Emirates; fatme.alanouti@zu.ac.ae

2 Institute of Public Health, College of Medicine and Health Sciences, United Arab Emirates University, Al Ain 17666, United Arab Emirates; luai.ahmed@uaeu.ac.ae

3 Department of Obstetrics and Gynecology, Ajman University, Ajman 20550, United Arab Emirates; azmatriazkhan@gmail.com

4 Sunlight, Nutrition and Health Research Center, P.O. Box 641603, San Francisco, CA 94164-1603, USA; wbgrant@infionline.net

5 Planning and Development Division, Government of Gilgit Baltistan, Gilgit 15100, Pakistan; nadir.shah.sun@gmail.com

6 Public Health Research Center, New York University Abu Dhabi, Abu Dhabi 129188, United Arab Emirates; ra107@nyu.edu

7 Department of Internal Medicine, College of Medicine and Health Sciences, United Arab Emirates University, Al Ain 17666, United Arab Emirates; j.kaabi@uaeu.ac.ae

8 Department of Family Medicine, Aga Khan University, Karachi 3500, Pakistan

* Correspondence: syeds@uaeu.ac.ae; Tel.: +92-971-3-713-7458

\begin{abstract}
Vitamin D is important for bone health, and vitamin D deficiency could be linked to noncommunicable diseases, including cardiovascular disease. The purpose of this study was to determine the prevalence of vitamin D deficiency and its associated risk factors among female migrants from Philippines, Arab, and South Asian countries residing in the United Arab Emirates (UAE). We used a cross-sectional study to recruit a random sample $(N=550)$ of female migrants aged 18 years and over in the city of Al Ain, UAE. Vitamin D deficiency was defined as serum 25hydroxyvitamin D concentrations $\leq 20 \mathrm{ng} / \mathrm{mL}$ (50 nmol/L). We used multivariable logistic regression analysis to identify risk factors associated with vitamin $\mathrm{D}$ deficiency. The mean age of participants was 35 years ( $\mathrm{SD} \pm 10$ ). The overall prevalence rate of vitamin D deficiency was $67 \%$ (95\% CI 60-73\%), with the highest rate seen in Arabs (87\%), followed by South Asians (83\%) and the lowest in Filipinas (15\%). Multivariate analyses showed that low physical activity (adjusted odds ratio $(\mathrm{aOR})=4.59$; $95 \%$ CI $1.98,10.63)$, having more than 5 years duration of residence in the UAE $(\mathrm{aOR}=4.65 ; 95 \% \mathrm{CI}$ : $1.31,16.53)$ and being obese $(\mathrm{aOR}=3.56 ; 95 \% \mathrm{CI} 1.04,12.20)$ were independently associated with vitamin D deficiency, after controlling for age and nationality. In summary, vitamin D deficiency was highly prevalent among female migrants, especially Arabs and South Asians. It is crucial that health professionals in the UAE become aware of this situation among this vulnerable subpopulation and provide intervention strategies aiming to rectify vitamin D deficiency by focusing more on sun exposure, physical activity, and supplementation.
\end{abstract}

Keywords: vitamin D status; prevalence; female migrants; United Arab Emirates

\section{Introduction}

Vitamin D deficiency remains a worldwide public health problem, affecting large proportions of the population in developed and the developing countries [1]. Vitamin D deficiency remains common in children and adults and the musculoskeletal consequences of inadequate vitamin D are well established. In utero and during childhood, vitamin D deficiency can lead to growth retardation and skeletal deformities including childhood 
rickets [2]. Vitamin D supplementation during pregnancy is associated with improved infant growth and reduction of fetal or neonatal mortality [3]. In adults, vitamin D deficiency can cause osteomalacia, muscle weakness and increased risk of fracture [4]. Although the strongest evidence for the effect of vitamin D deficiency is related to skeletal disorders, low concentrations of vitamin $\mathrm{D}$ are associated with several non-skeletal disorders including cardiovascular diseases, several types of cancer, neurodegenerative diseases, disorders of glucose metabolism, and a possible role in the recently emerging pandemic of COVID-19 [5-8].

The extreme consequences of vitamin D deficiency, such as rickets in children and osteomalacia in adults, have been almost eliminated in some developed countries through adequate diet, food fortification, and the encouragement of moderate sunlight exposure [9]. Paradoxically, populations in the Middle East and North Africa (MENA) region have some of the lowest serum 25-hydroxy-vitamin D [25(OH)D] concentrations worldwide, despite the abundance of sunshine throughout the year $[10,11]$.

Vitamin D deficiency among women in Arab countries has been attributed to inadequate exposure of skin to sunlight due to a very conservative style of dress that covers most of the body when they are outdoors [11,12]. In a study of Arab-American women, there was a significantly higher prevalence of vitamin D deficiency in women practicing a conservative style of dress, compared to their counterparts practicing a less conservative dressing [13,14]. We previously examined the prevalence of vitamin D deficiency among adolescents aged 15 to 18 years in the city of Al Ain, UAE. A higher proportion (32.0\%) of female adolescents had vitamin $\mathrm{D}$ deficiency as compared to their male counterparts $(8.0 \%)$ [15].

Given the remarkably high percentage of working migrants, known as 'guest workers' or 'expatriates', the UAE is one of the most culturally diverse countries. Expatriate foreign workers account for almost $80 \%$ of the UAE's total population [16]. A significant proportion of female migrant workers, including women from various Arab countries, South Asia, and Philippines are typically employed for indoor work activities, such as domestic or office work, sales, and beauty salons.

Migrant workers are among the most vulnerable populations that could be afflicted with vitamin D deficiency [17]. This study aimed to estimate the prevalence of vitamin $\mathrm{D}$ deficiency and examine the correlates of low levels of serum 25(OH)D concentrations among Arab, South Asian, and Filipina migrants residing in the UAE. To our knowledge this is the first research investigation that targets this under-studied subpopulation to assess the burden of vitamin D deficiency and pave for future studies that could aim to address such an important public health issue.

\section{Methods}

\subsection{Study Design and Ethics}

The study employed a cross-sectional design. We obtained a College of Medicine and Health Sciences, UAE individual faculty grant for the project, entitled "Chronic Diseases Prevention in Immigrants: putting CVD risk factors on surveillance screen". Ethical approval was obtained from the Al Ain Medical District Human Research (AAMDHREC 10/21) and study participants provided written informed consent.

\subsection{Selection of Study Participants}

The target study population consisted of female Arab, South Asian, and Filipina migrant workers aged 18 years and older. We used the formula for binomial distribution $\left(n={ }^{z} z \alpha^{2} \mathrm{p}(1-\mathrm{p}) / \mathrm{d}^{2}\right)$ to estimate the sample size, where $(\mathrm{n})$ is the sample size, $(\mathrm{z} \alpha)$ is the normal deviate (1.96) at $5 \%$ level of significance, $(p)$ is the prevalence, and (d) is the precision. Assuming a precision or tolerable variation of \pm 0.06 around an estimated prevalence of $70 \%$ for vitamin D deficiency in women [9], a sample of 200 participants would be needed.

All expatriate workers seeking employment or renewing their visa in the UAE are required by law to undergo health and communicable disease screening. The sampling 
frame in this study was a list of all expatriate workers from the Arab region, South Asia, and Philippines who were enrolled for medical examination at the only visa screening center in the city of $\mathrm{Al}$ Ain, Abu Dhabi emirate, during the process of either obtaining a new visa or renewing it over a period of six months [18].

\subsection{Inclusion Criteria}

Female migrant workers who were of an Arab, South Asian, or Philippines' nationality, aged $\geq 18$ years, were able to read and speak Arabic, Urdu, Hindi, Bengali, or Filipino, and to provide a written informed consent were eligible to participate in the study. Due to the low literacy rate among the South Asian expatriate population in the UAE [16], the study questionnaire was interviewer-administered, and all interviews were conducted in Urdu, Hindi, Bengali, or Filipino, and led by native Urdu, Hindi, Bengali or Filipino speaking research assistants who had received appropriate training. Eligible participants registered for the visa screening were invited to participate in the study which spanned over six months to complete recruitment of the required sample.

\subsection{Measures}

We used an adapted version of the World Health Organization (WHO) global standard "STEPS" survey questionnaire entitled "Chronic Diseases Prevention in Immigrants: putting CVD risk factors on surveillance screen" for population-based assessment of the prevalence of noncommunicable diseases (NCDs) risk factors including vitamin D deficiency [19].

A $5 \mathrm{~mL}$ venous fasting blood sample was obtained from the study participants by qualified nurses using standardized tubes. Blood samples were immediately transferred to Tawam Hospital (Al Ain) laboratory where they underwent standardized (quality controlled) analyses. Serum $25(\mathrm{OH}) \mathrm{D}$ concentrations were measured by radioimmunoassay (DiaSorin, Stillwater, Minnesota, MN, USA). The intra-assay and inter-assay for coefficients of variation were $8.3 \%$ and $3.2 \%$ respectively. We used the reference value for serum $25(\mathrm{OH}) \mathrm{D}$ concentrations $<20 \mathrm{ng} / \mathrm{mL}$ ( $50 \mathrm{nmol} / \mathrm{L}$ ) to define vitamin D deficiency [4].

We collected information on demographics, lifestyle factors, family and personal disease history, home country residence setting (rural, urban), occupation, and monthly salary in UAE dirham or AED (USD1.00 AED3.67).

Studies in migrants from Western developed countries indicated a decline in health with the increased duration of stay, which could be attributed to the adoption of local behaviors and norms and diet, also known as acculturation [20]. We used the duration of residence as a marker to evaluate the effect of acculturation on vitamin D status among the participants [21].

Participants' weight and height measurements were performed using standard weight and height scales (SECA, Hamburg, Germany). Body mass index (BMI) was calculated as weight in kilograms divided by the square of the height in meters and BMI categorization was based on WHO recommendations: being overweight (BMI 25.0 to $29.9 \mathrm{~kg} / \mathrm{m}^{2}$ ), and obesity $\left(\geq 30.0 \mathrm{~kg} / \mathrm{m}^{2}\right)$ [22]. Resting brachial blood pressure (BP) was measured using a calibrated automated BP measurement device (Omron HEM-705cp) in sitting position using the right upper arm and an appropriately sized cuff after a period of five minutes' rest. The average of two measures taken was used for analysis. Hypertension (HTN) was defined as being on anti-hypertensive medications or having a systolic blood pressure $\geq 140 \mathrm{mmHg}$ or a diastolic blood pressure $\geq 90 \mathrm{mmHg}$ [23]. Study participants were classified as current smokers if they answered yes to the question, "have you ever smoked cigarettes, cigars or shisha?". Information on physical activity was obtained using the International Physical Activity Questionnaire (IPAQ-short version) [24]. We measured the frequency (days per week) and duration (minutes per day) of moderate- and vigorous-intensity physical activity in a period of seven-days prior to the survey. Physical activity was based on recall of daily activity patterns in the previous 7 days. Using the US guideline for physical activity, recommended by the Centers for Disease Control and Prevention (CDC) and the American College of Sports Medicine (ACSM), we identified the proportion of participants reporting 
moderate-intensity physical activity for a minimum of $30 \mathrm{~min}$ on five days each week or vigorous-intensity physical activity for a minimum of $20 \mathrm{~min}$ on three days each week [25].

\subsection{Statistical Analysis}

Data were analyzed using SPSS version 27.0 (IBM, Armonk, NY, USA). Categorical variables were presented as frequencies and percentages. Continuous variables were presented as mean \pm standard deviation. Participants were grouped into three categories based on serum $25(\mathrm{OH}) \mathrm{D}$ levels and all variables were compared using Chi-Square test for categorical variables and One-Way Analysis of Variance (ANOVA) for continuous variables. Moreover, differences in results among the participants (Arabs, Asians, Filipinas) were explored using Chi-Square test for categorical variables and Independent-Samples $t$-Test for continuous variables. Simple and multivariate ordered logistic regression models were constructed to determine the predictors of vitamin D deficiency. Simple and multivariate binary logistic regression models were considered to identify the variables associated with vitamin D deficiency. A $p$-value of $<0.05$ was considered statistically significant in our analyses.

\section{Results}

The mean age of study participants was 35 years (SD \pm 10$), 33$ years $(S D \pm 8)$ for Filipinas, 37 years $(S D \pm 11)$ for Arabs, and 34 years $(S D \pm 10)$ for South Asian. Table 1 shows the characteristics of the study population.

Table 1. Characteristics of the female migrant participants living in Al Ain, UAE.

\begin{tabular}{|c|c|c|c|c|c|c|c|}
\hline \multirow[t]{2}{*}{ Variable } & \multirow[b]{2}{*}{$N$} & \multicolumn{2}{|c|}{ Filipinas } & \multicolumn{2}{|c|}{ Arab } & \multicolumn{2}{|c|}{ South Asian } \\
\hline & & $n$ & $\%$ & $n$ & $\%$ & $n$ & $\%$ \\
\hline All & 553 & 290 & 52.4 & 136 & 24.6 & 127 & 23.0 \\
\hline \multicolumn{8}{|l|}{ Age, (years) } \\
\hline $18-30$ & 186 & 123 & $(43.0)$ & 43 & $(31.6)$ & 55 & $(43.7)$ \\
\hline $31-40$ & 171 & 119 & $(41.6)$ & 45 & (33.3) & 39 & (39.9) \\
\hline$\geq 41$ & 191 & 44 & $(15.4)$ & 47 & $(34.8)$ & 32 & $(25.4)$ \\
\hline \multicolumn{8}{|l|}{ Education of the participant } \\
\hline No formal schooling & 39 & 15 & $(5.2)$ & 15 & $(11.2)$ & 9 & $(7.3)$ \\
\hline Up to secondary & 203 & 124 & $(43.2)$ & 40 & $(29.8)$ & 59 & (31.4) \\
\hline College or higher & 303 & 148 & $(51.6)$ & 79 & $(59.0)$ & 76 & $(61.3)$ \\
\hline \multicolumn{8}{|l|}{ Marital status } \\
\hline Unmarried & 194 & 137 & $(49.6)$ & 34 & $(25.6)$ & 23 & $(18.6)$ \\
\hline Married & 306 & 118 & $(42.8)$ & 89 & $(66.9)$ & 99 & (79.8) \\
\hline Divorced, or widowed & 33 & 21 & $(7.6)$ & 10 & $(7.5)$ & 2 & $(1.6)$ \\
\hline \multicolumn{8}{|l|}{ Occupation } \\
\hline Housemaid & 192 & 176 & 63.6 & 8 & 6.2 & 8 & 6.8 \\
\hline Housewife & 122 & 4 & 1.4 & 64 & 49.6 & 54 & 45.8 \\
\hline Driver & 10 & 10 & 3.6 & 0 & 0 & 0 & 0.0 \\
\hline Cook & 10 & 10 & 3.6 & 0 & 0 & 0 & 0.0 \\
\hline Administrator, supervisor & 35 & 21 & 7.6 & 7 & 5.4 & 7 & 5.9 \\
\hline Teacher & 36 & 5 & 1.8 & 16 & 12.4 & 15 & 12.7 \\
\hline Health care worker & 55 & 23 & 8.3 & 13 & 10.1 & 19 & 16.1 \\
\hline Other & 64 & 28 & 10.1 & 21 & 16.3 & 15 & 12.7 \\
\hline \multicolumn{8}{|c|}{ Monthly income, AED (1 USD = 3.6 AED) } \\
\hline Lowest (812.6) & 133 & 125 & $(52.5)$ & 5 & $(13.2)$ & 3 & $(6.5)$ \\
\hline Middle (1365.8) & 85 & 72 & (30.3) & 5 & $(13.2)$ & 8 & $(17.4)$ \\
\hline Highest (7422.8) & 104 & 41 & $(17.2)$ & 28 & $(73.6)$ & 35 & $(76.1)$ \\
\hline \multicolumn{8}{|l|}{ Residence in home country, $n(\%)$} \\
\hline Urban & 263 & 129 & $(50.8)$ & 54 & $(43.2)$ & 80 & $(67.2)$ \\
\hline Rural & 235 & 125 & $(49.2)$ & 71 & $(56.8)$ & 39 & $(32.8)$ \\
\hline \multicolumn{8}{|l|}{ Duration of residence in UAE } \\
\hline$<1$ year & 185 & 133 & $(53.0)$ & 27 & $(22.9)$ & 25 & $(22.9)$ \\
\hline 1 to 5 years & 208 & 106 & $(42.2)$ & 43 & $(36.4)$ & 59 & $(54.1)$ \\
\hline$\geq 5$ years & 85 & 12 & $(4.8)$ & 48 & $(40.7)$ & 25 & (23.0) \\
\hline
\end{tabular}


Table 1. Cont.

\begin{tabular}{|c|c|c|c|c|c|c|c|}
\hline \multirow[t]{2}{*}{ Variable } & \multirow[b]{2}{*}{$N$} & \multicolumn{2}{|c|}{ Filipinas } & \multicolumn{2}{|c|}{ Arab } & \multicolumn{2}{|c|}{ South Asian } \\
\hline & & $n$ & $\%$ & $n$ & $\%$ & $n$ & $\%$ \\
\hline \multicolumn{8}{|l|}{ Moderate or vigorous physical activity } \\
\hline Yes & 161 & 133 & $(45.9)$ & 15 & $(11.0)$ & 13 & $(10.2)$ \\
\hline No & 391 & 157 & $(54.1)$ & 121 & $89.0)$ & 114 & $(89.8)$ \\
\hline \multicolumn{8}{|l|}{ Body mass index categories } \\
\hline$<25.0$ & 294 & 187 & $(64.5)$ & 44 & $(32.4)$ & 63 & $(49.6)$ \\
\hline $25-30$ & 166 & 83 & $(28.6)$ & 41 & $(30.1$ & 42 & $(33.1)$ \\
\hline$\geq 30.0$ & 93 & 20 & $(6.9)$ & 51 & $(37.5)$ & 22 & $(17.3)$ \\
\hline \multicolumn{8}{|l|}{ Cigarette smoking, currently } \\
\hline No & 514 & 268 & $(92.4)$ & 122 & $(89.7)$ & 124 & $(97.6)$ \\
\hline Yes & 39 & 22 & $(7.6)$ & 14 & $(10.3)$ & 3 & $(2.4)$ \\
\hline \multicolumn{8}{|l|}{ Alcohol consumption } \\
\hline No & 448 & 193 & $(66.6)$ & 135 & $(99.3)$ & 120 & $(94.5)$ \\
\hline Yes & 105 & 97 & $(33.4)$ & 1 & $(0.7)$ & 7 & $(5.5)$ \\
\hline \multicolumn{8}{|l|}{ Hemoglobin A1c level } \\
\hline$<5.7 \%$ & 151 & 52 & $(91.2)$ & 64 & $(71.1)$ & 35 & $(53.9)$ \\
\hline $5.7-6.4 \%$ & 38 & 4 & $(7.0)$ & 15 & $(16.7)$ & 19 & $(29.2)$ \\
\hline$\geq 6.5 \%$ & 23 & 1 & $(1.8)$ & 11 & $(12.2)$ & 11 & $(16.9)$ \\
\hline Blood pressure, $\mathrm{mm} \mathrm{Hg}$ & 363 & 188 & $(64.8)$ & 93 & $(68.4)$ & 82 & $(64.6)$ \\
\hline$<140 / 90$ & 190 & 102 & $(35.2)$ & 43 & $(31.6)$ & 45 & $(35.4)$ \\
\hline \multicolumn{8}{|c|}{$\geq 140 / 90$ or on hypertension medication } \\
\hline \multicolumn{8}{|c|}{ Levels of the serum $25(\mathrm{OH}) \mathrm{D}$ concentrations $(\mathrm{ng} / \mathrm{mL})$} \\
\hline Mean $(\mathrm{ng} / \mathrm{mL},( \pm \mathrm{SD})$ & $20( \pm 12)$ & 30 & $( \pm 11)$ & 14 & $( \pm 10)$ & 15 & $( \pm 9)$ \\
\hline \multicolumn{8}{|c|}{ Serum $25(\mathrm{OH}) \mathrm{D}$ concentrations by category } \\
\hline$>20 \mathrm{ng} / \mathrm{mL}(50 \mathrm{nmol} / \mathrm{L}), n(\%)$ & $71(33.3)$ & 48 & $(84.2)$ & 12 & $(13.3)$ & 11 & $(16.7)$ \\
\hline$\leq 20 \mathrm{ng} / \mathrm{mL}(50 \mathrm{nmol} / \mathrm{L})$ & $142(66.7)$ & 9 & $(15.8)$ & 78 & $(86.7)$ & 55 & $(83.3)$ \\
\hline
\end{tabular}

Data are presented as $N$ and $n(\%)$; data presented as mean \pm SD.

A significant proportion (7.2\%) had no formal schooling, 37.2\% had secondary level education and $55.6 \%$ had college or higher levels of education. A high proportion (57.4\%) were married, $36.4 \%$ were unmarried and $6.2 \%$ were divorced or widowed. A high proportion of study participants worked as housemaids $(36.6 \%)$ and housewives $(23.3 \%)$. The rest were health care workers $(10.5 \%)$, teachers $(6.9 \%)$, administrators or supervisors $(6.7 \%)$, drivers or cooks $(4 \%)$, and multitude of other activities $(10.5 \%)$. With regards to background in home country, $52.8 \%$ were from urban settings while $47.2 \%$ had rural backgrounds. The prevalence of obesity in Filipinas was notably low (6.9\%) as compared to their Arabs (37.5\%) and South Asians (17.3\%) counterparts. Moderate and vigorous physical activity was reported by a higher proportion of Filipinas (45.9\%) as compared to Arab (11.0\%) and South Asian (10.2\%) female immigrants.

Table 2 shows the mean \pm SD of $25(\mathrm{OH}) \mathrm{D}$ concentrations and vitamin D deficiency in the study population.

Table 2. Distribution of inadequate $25(\mathrm{OH}) \mathrm{D}$ levels $(\mathrm{ng} / \mathrm{mL})$ among the female migrant participants according to sociodemographic, lifestyle, and clinical characteristics.

\begin{tabular}{|c|c|c|c|c|c|c|c|}
\hline \multirow[t]{3}{*}{ Variable } & \multicolumn{7}{|c|}{ 25(OH)D Levels (ng/mL) } \\
\hline & \multirow[b]{2}{*}{$N$} & \multirow[b]{2}{*}{ Mean } & \multirow[b]{2}{*}{$( \pm \mathrm{SD})$} & \multicolumn{4}{|c|}{$<20 \mathrm{ng} / \mathrm{mL})$} \\
\hline & & & & $p$ & $\%$ & $(95 \% \mathrm{CI})$ & $p$ \\
\hline All & 213 & 19 & $(11)$ & & 66.7 & $(60.0-72.7)$ & \\
\hline \multicolumn{8}{|l|}{ Age, (years) } \\
\hline $18-34$ & 113 & 18 & $(12)$ & 0.37 & 68.1 & $(58.9-76.1)$ & 0.38 \\
\hline $35-44$ & 57 & 20 & (14) & & 59.6 & $(47.1-72.2)$ & \\
\hline$\geq 45$ & 43 & 18 & (11) & & 72.1 & $(55.8-83.2)$ & \\
\hline
\end{tabular}


Table 2. Cont.

\begin{tabular}{|c|c|c|c|c|c|c|c|}
\hline \multirow[t]{3}{*}{ Variable } & \multicolumn{7}{|c|}{ 25(OH)D Levels (ng/mL) } \\
\hline & \multirow[b]{2}{*}{$N$} & \multirow[b]{2}{*}{ Mean } & \multirow[b]{2}{*}{$( \pm \mathbf{S D})$} & \multicolumn{4}{|c|}{$<20 \mathrm{ng} / \mathrm{mL})$} \\
\hline & & & & $p$ & $\%$ & $(95 \% \mathrm{CI})$ & $p$ \\
\hline \multicolumn{8}{|l|}{ Nationality } \\
\hline Filipinas & 57 & 30 & (12) & $<0.001$ & 15.8 & $(8.3-27.8)$ & $<0.001$ \\
\hline Arab & 90 & 14 & (10) & & 86.7 & $(77.8-92.3)$ & \\
\hline South Asian & 66 & 15 & (9) & & 83.3 & $(72.2-90.6)$ & \\
\hline \multicolumn{8}{|l|}{ Education of the participant } \\
\hline No formal schooling & 18 & 17 & (15) & 0.02 & 77.8 & $(52.6-91.7)$ & $<0.001$ \\
\hline Up to secondary & 91 & 22 & (13) & & 49.4 & $(39.2-59.7)$ & \\
\hline College or higher & 101 & 17 & (10) & & 79.2 & $(70.1-86.1)$ & \\
\hline \multicolumn{8}{|l|}{ Marital status } \\
\hline Unmarried & 69 & 21 & (13) & 0.26 & 56.5 & $(44.5-67.58$ & 0.06 \\
\hline Married & 129 & 18 & (11) & & 72.9 & $(64.5-79.8)$ & \\
\hline Divorced, or widowed & 10 & 19 & $(12)$ & & 60.0 & $(28.2-85.1)$ & \\
\hline \multicolumn{8}{|l|}{ Occupation } \\
\hline Housemaid & 64 & 29 & (12) & $<0.001$ & 21.9 & $(13.3-33.8)$ & $<0.001$ \\
\hline Housewife & 71 & 14 & (9) & & 88.7 & (78.9-94.3) & \\
\hline Driver & 8 & 12 & (7) & & 87.5 & $(31.9-98.1)$ & \\
\hline Administrator, supervisor & 9 & 14 & (5) & & 77.8 & $(39.6-94.9)$ & \\
\hline Teacher & 21 & 15 & (10) & & 80.9 & $(58.0-92.9)$ & \\
\hline Health care worker & 18 & 18 & $(8)$ & & 77.8 & (52.6-91.7) & \\
\hline Other & 22 & 14 & (13) & & 90.9 & (69.1-97.8) & \\
\hline \multicolumn{8}{|l|}{$\begin{array}{l}\text { Monthly income, Dirham (AED) } \\
\text { (US dollar = } 3.7 \text { AED) }\end{array}$} \\
\hline Lowest (801.2) & 42 & 29 & 12 & $<0.001$ & 23.8 & $(13.1-39.3)$ & $<0.001$ \\
\hline Middle (1386.3) & 19 & 24 & 13 & & 36.8 & $(18.1-60.6)$ & \\
\hline Highest (8397.5) & 40 & 17 & 13 & & 80.0 & $(64.4-89.8)$ & \\
\hline \multicolumn{8}{|l|}{ Residence, $\mathrm{n}(\%)$} \\
\hline Urban & 84 & 19 & 13 & 0.74 & 65.5 & $(54.6-74.9)$ & 0.57 \\
\hline Rural & 114 & 19 & 12 & & 69.3 & $(60.1-77.1)$ & \\
\hline \multicolumn{8}{|l|}{ Duration of residence in UAE } \\
\hline$<1$ year & 62 & 22 & 14 & 0.005 & 56.4 & $(43.8-68.2)$ & $<0.001$ \\
\hline 1 to 5 years & 72 & 18 & 11 & & 65.3 & $(53.5-75.4)$ & \\
\hline$\geq 5$ years & 49 & 14 & 14 & & 91.8 & $(79.69-96.9)$ & \\
\hline \multicolumn{8}{|l|}{ Physical activity (mod/vigorous.) } \\
\hline Yes & 52 & 25 & 13 & $<0.001$ & 42.3 & $(29.5-56.2)$ & $<0.001$ \\
\hline No & 161 & 17 & 11 & & 75.5 & $(67.2-80.7)$ & \\
\hline Body mass index categories & & & & 0.002 & & & \\
\hline$<25.0$ & 94 & 21 & 13 & & 57.4 & $(47.62-67.1)$ & 0.007 \\
\hline $25-30$ & 74 & 19 & 12 & & 67.6 & $(55.9-77.3)$ & \\
\hline$\geq 30.0$ & 45 & 14 & 8 & & 84.4 & $(70.5-92.4)$ & \\
\hline \multicolumn{8}{|l|}{ Cigarette smoking, currently } \\
\hline No & 199 & 19 & 12 & 0.99 & 65.3 & $(17.1-20.5)$ & 0.12 \\
\hline Yes & 14 & 19 & 16 & & 85.7 & $(9.5-28.0)$ & \\
\hline \multicolumn{8}{|l|}{ Alcohol use } \\
\hline No & 197 & 18 & 12 & $<0.001$ & 71.1 & $(64.3-77.0)$ & $<0.001$ \\
\hline Yes & 16 & 32 & 13 & & 12.5 & $(2.9-39.9)$ & \\
\hline \multicolumn{8}{|l|}{ Hemoglobin A1c level } \\
\hline$<5.7 \%$ & 151 & 20 & 13 & 0.29 & 62.2 & $(54.2-69.7)$ & 0.11 \\
\hline $5.7-6.4 \%$ & 38 & 16 & 8 & & 79.9 & $(62.8-89.2)$ & \\
\hline$\geq 6.5 \%$ & 23 & 19 & 13 & & 73.9 & $(52.1 .3$ & \\
\hline \multicolumn{8}{|l|}{ Blood pressure, $\mathrm{mm} \mathrm{Hg}$} \\
\hline$<140 / 90$ & 139 & 18 & 13 & 0.45 & 70.5 & $(62.3-77.5)$ & 0.10 \\
\hline$\geq 140 / 90$ or on hypertension medication & 74 & 20 & 11 & & 59.5 & $(47.8-70.1)$ & \\
\hline
\end{tabular}

Data are presented as frequencies (\%) and mean $\pm \mathrm{SD}$ and odds ratio (OR) $(95 \% \mathrm{CI}) ; p<0.05$ considered significant (shown in boldface).

Overall, the 25(OH)D concentrations were $20 \pm 11 \mathrm{ng} / \mathrm{mL}$ in the study population, specifically $30 \pm 11$ in the Filipinas, $14 \pm 10$ in Arabs, and $15 \pm 9$ in South Asians. The 
overall prevalence rate of vitamin D deficiency $(25(\mathrm{OH}) \mathrm{D} \leq 20 \mathrm{ng} / \mathrm{mL})$ was $66.7 \%(95 \% \mathrm{CI}$, $60.0 \%-72.7 \%$ ). Examination of the prevalence rate of vitamin $\mathrm{D}$ deficiency by age revealed insignificant variations. There were significant differences in $25(\mathrm{OH}) \mathrm{D}$ concentrations as well as the prevalence rate of vitamin D deficiency by nationality, education level, occupation, income, duration of residence in the UAE, physical activity, body mass index categories, and self-reported alcohol use. There was an inverse correlation between earnings and vitamin D status and similarly an inverse correlation between a high education level and lower vitamin D status. This was due to the fact that vitamin D deficiency is much lower (15.8\%) when compared to Arab (86.7\%) and South Asian (83.3), as shown in Table 1. A high proportion of Filipinas $(52.5 \%)$ were in the lowest tertile of monthly earning when compared to Arab (13.2\%) and South Asian (6.5\%) in the lowest tertile of monthly earning. Similarly, a high proportion of Arab and South Asian had college or higher level of education. A high proportion of Filipinas reported alcohol consumption (33.4\%) compared to their (Arab $(0.7 \%)$ and South Asian (5.55) counterparts.

The boxplot of participants' serum 25(OH)D concentrations ( $\mathrm{ng} / \mathrm{mL}$ ) according to BMI categories in Figure 1 demonstrates the low levels of $25(\mathrm{OH}) \mathrm{D}$ concentrations (ng/dL) among overweight and obese participants. Figure 2 shows participants' 25(OH)D concentrations levels overall, and by the nationality.

Table 3 summarizes the results from multivariate analyses. After adjusting for all related factors, including age and nationality, low physical activity $(\mathrm{AOR}=4.59 ; 95 \% \mathrm{CI}$ 1.1.98-10.63), having more than 5 years duration of residence in UAE (AOR $=4.65 ; 95 \%$ CI 1.31-16.53), and being obese ( $\mathrm{AOR}=3.56$; 95\% CI 1.04-12.20) were independently associated with vitamin $\mathrm{D}$ deficiency.

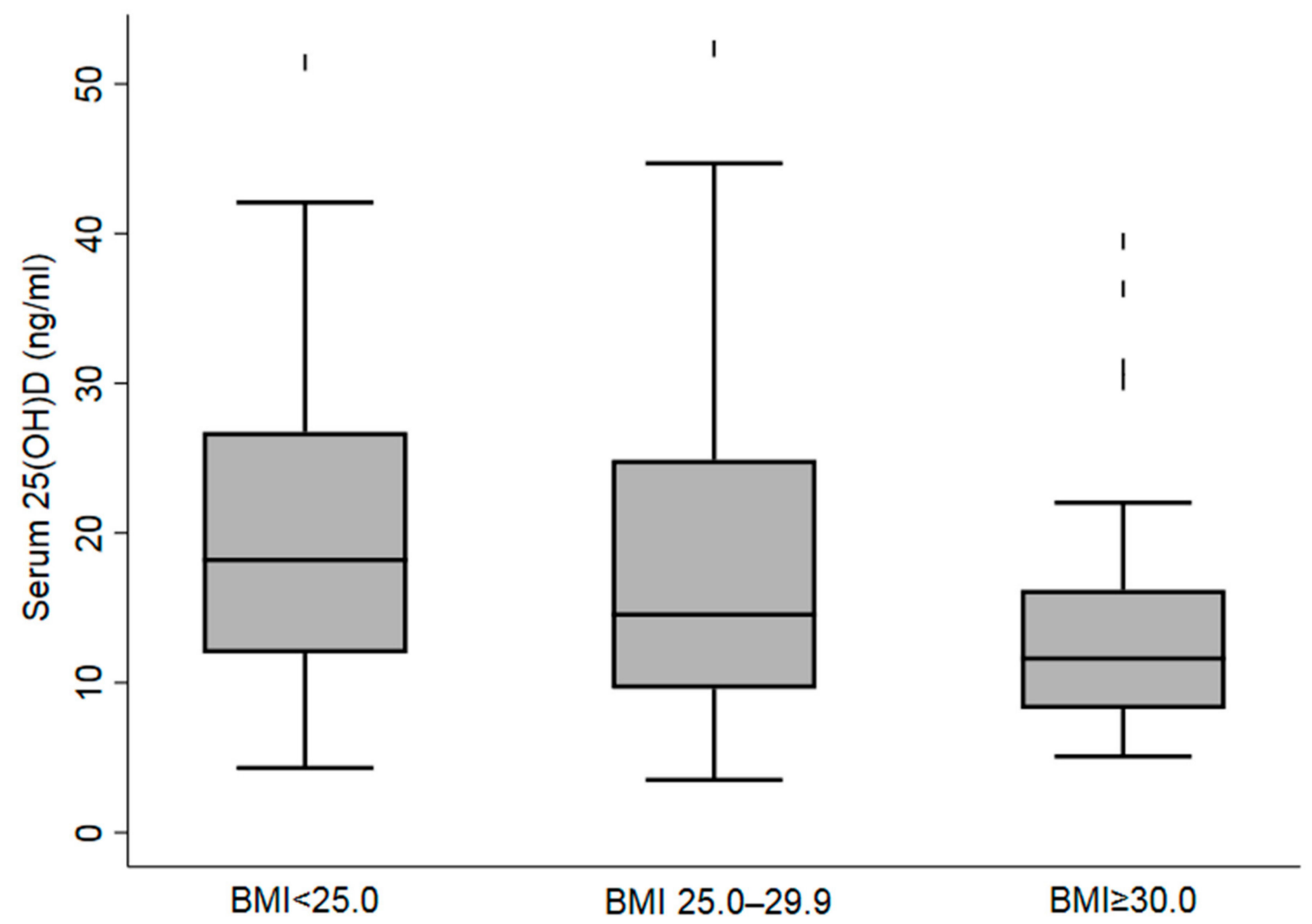

Figure 1. Boxplot of Serum 25(OH)D Concentrations according to Body Mass Index in the Female Migrant Participants Living in Al Ain, UAE. 


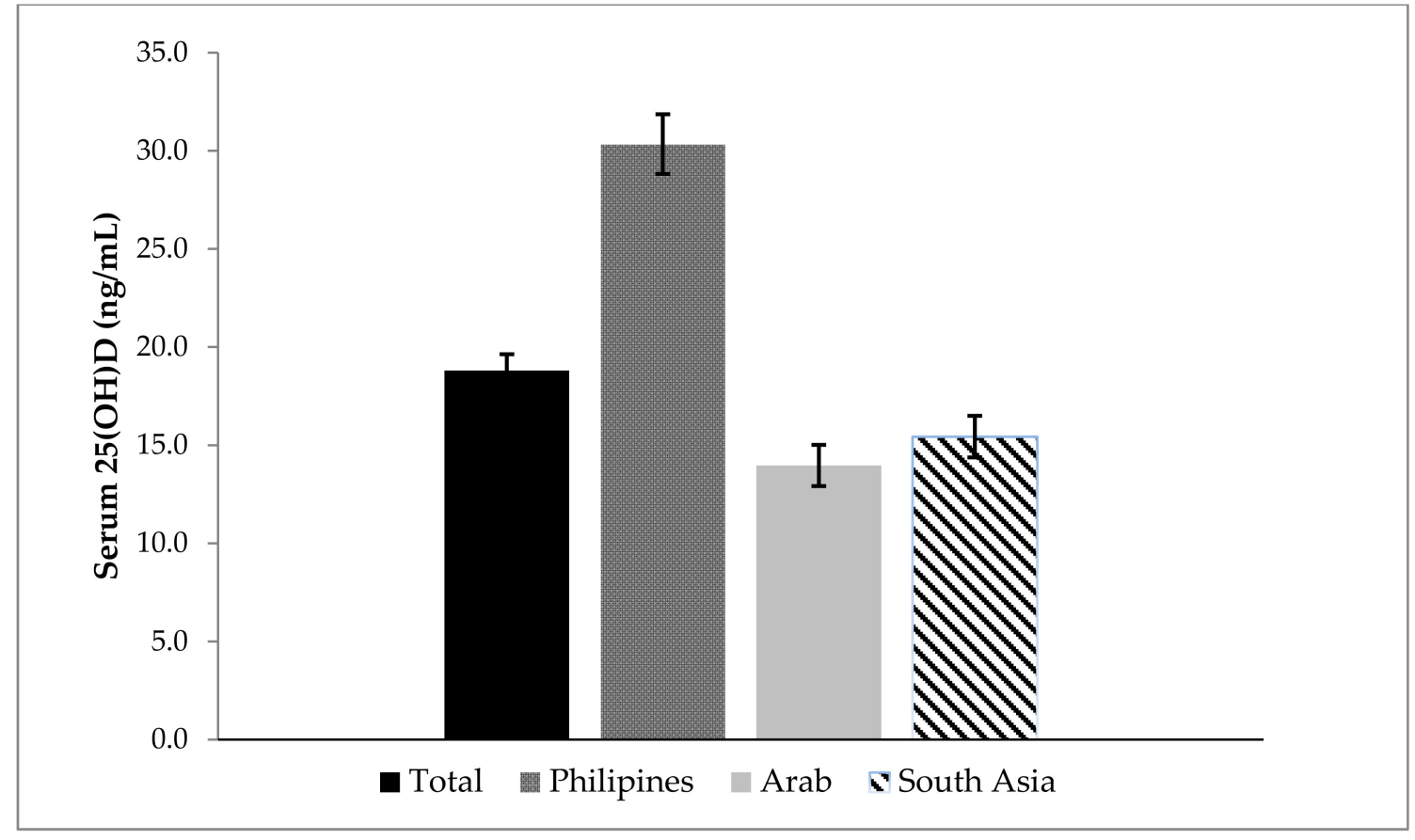

Figure 2. Mean Serum 25(OH)D Concentrations \pm SEM in the Females Migrant Participants Living in Al Ain, UAE.

Table 3. Multivariate logistic regression analysis for vitamin D deficiency correlates among the female migrant participants.

\begin{tabular}{|c|c|c|c|}
\hline Determinants & Adjusted & & \\
\hline & OR & $95 \%$ CI & $p$ \\
\hline Age in years & 0.97 & $(0.92-1.01)$ & 0.18 \\
\hline \multicolumn{4}{|l|}{ Nationality } \\
\hline Filipinas & 0.06 & $(0.01-0.42)$ & 0.004 \\
\hline Arab & Reference & & \\
\hline South Asian & 0.79 & $(0.32-1.98)$ & 0.62 \\
\hline \multicolumn{4}{|l|}{ Education } \\
\hline No formal education & Reference & & \\
\hline Up to secondary & 0.24 & $(0.05-1.04)$ & 0.06 \\
\hline College or higher & 0.66 & $0.15-2.89)$ & 0.59 \\
\hline \multicolumn{4}{|c|}{ Duration of residence in UAE } \\
\hline$\leq 1$ year & Reference & & \\
\hline$>1$ to 5 years & 0.78 & $(0.33-1.83)$ & 0.67 \\
\hline$>5$ years & 4.65 & $(1.31-16.53)$ & 0.02 \\
\hline \multicolumn{4}{|l|}{ Body mass index categories } \\
\hline \multicolumn{4}{|l|}{ BMI } \\
\hline$<24.99$ & Reference & & \\
\hline $25-29.99$ & 2.21 & $(0.92-5.30)$ & 0.08 \\
\hline$\geq 30.0$ & 3.56 & $(1.04-12.20)$ & 0.04 \\
\hline \multicolumn{4}{|c|}{ Low level of physical activity * } \\
\hline No & Reference & & \\
\hline Yes & 4.59 & $(1.98-10.63)$ & $<0.001$ \\
\hline
\end{tabular}

\section{Discussion}

This study showed the extent of vitamin D deficiency among female migrants. Vitamin D deficiency was especially common among Arab and South Asian migrants. Using serum $25(\mathrm{OH}) \mathrm{D}$ concentrations $\leq 20 \mathrm{ng} / \mathrm{mL}$ as a cutoff to define vitamin $\mathrm{D}$ deficiency, our 
data demonstrated that over $80 \%$ of female migrants from Arab and South Asian countries were vitamin D deficient. A retrospective study of the UAE population on 60,979 subjects originating from 136 different countries revealed that $78.9 \%$ of expatriates were suffering from hypovitaminosis, with more females being afflicted with severe deficiency [26]. Previous studies have shown lower prevalence among adults in developed countries, 24\% in US [27], 37\% in Canada [28], 32\% in Australia [29], and 40\% in the European countries [30]. Paradoxically, vitamin D deficiency of up to $80 \%$ was observed in Middle Eastern Arab countries despite the sunny weather [10,31]. Moreover, a systematic review and meta-analysis of the prevalence of vitamin D deficiency among the population of Africa on 21,474 individuals from 23 countries within the continent revealed the prevalence was higher than speculated at a rate of $34 \%$; with women having remarkably lower $25(\mathrm{OH}) \mathrm{D}$ concentrations compared to men. It was concluded that being a female and living in urban areas in the northern and southern parts of Africa were associated with a higher risk of developing vitamin D deficiency [32]. The findings in the current study were in concordance with previous studies, and similarly documented a high prevalence of vitamin D deficiency among Arab female migrants originating from African and Middle Eastern countries. The reasons for vitamin D deficiency in Arab female migrants might include wearing conservative skin-concealing clothes, relatively high obesity, and low dietary vitamin D intake $[9,10]$. An additional factor might be related to dark skin complexion since the skin pigment melanin absorbs sunlight and dark skin color reduces the capacity of skin to synthesize vitamin $\mathrm{D}_{3}$ [33]. National examination surveys in the US indicated that over $80 \%$ of non-Hispanic black American adults, including men and women, had $\leq 20 \mathrm{ng} / \mathrm{mL}$ serum 25(OH)D concentrations [34,35].

Among South Asian females, 83.3\% were vitamin D deficient in the present investigation. A recent systematic review and meta-analysis of vitamin D deficiency in Asia involving 472 studies on 746,564 individuals demonstrated that region and altitude were important correlates of vitamin D deficiency [36]. Data from different parts in India revealed a $70 \%$ prevalence of vitamin $\mathrm{D}$ deficiency among adult with a higher prevalence of up to 79\% among females [37]. Studies conducted among South Asians in Australia, Canada, European countries, UK, and USA have found a prevalence of vitamin D deficiency in epidemic proportions compared to their native counterparts [34]. The proposed causes of vitamin D deficiency among South Asians in Western countries included low vitamin D intake, relatively high obesity prevalence, less exposure to sunlight, and wearing conservative clothes for cultural and religious reasons [38].

The low prevalence of vitamin D deficiency among Filipina migrants as compared to the South Asian and Arabs might be due to the lower prevalence of both obesity and physical inactivity [39]. However, additional confounders could also be involved including differences in dietary intake of vitamin D (as Filipinas highly consume oily fish) and dissimilarities in sartorial and lifestyle habits, which might entail more sun exposure and hence concomitant photosynthesis of vitamin D [40].

In our study, low physical activity, acculturation as measured by more than 5 years of residency in the UAE, and obesity were all independently associated with vitamin D deficiency. Physical activity was a significant independent predictor of vitamin D deficiency in several previous studies. Additionally, some researchers showed that serum $25(\mathrm{OH}) \mathrm{D}$ levels are affected by both physical activity and BMI in the context of obesity [41,42]. Pragmatically speaking, the positive impact of physical activity on vitamin $\mathrm{D}$ status could be attributed to metabolism upon energy disbursement with muscle contractions; however, when performed alfresco, it stimulates the conversion of dermal 7-dehydrocholesterol into vitamin D by solar UV-B rays [43]. The effect of physical activity could be complex, since physical inactivity is a well-established risk factor for overweight and obesity, which, in turn, could predispose to vitamin D deficiency through adipose sequestration and volumetric dilution of $25(\mathrm{OH}) \mathrm{D}$ [44]. Nevertheless, a study on older adults revealed a favorable correlation between physical activity and serum $25(\mathrm{OH}) \mathrm{D}$ levels over time regardless of exposure to sun [45]. In agreement with our results, numerous population-based investigations had demonstrated that obesity and reduced physical activity were independent 
determinants of vitamin D deficiency in South Asia [46], Philippines [40], Middle East [47], Europe, Australia, [29] and the US [35].

Obese females (BMI $\geq 30$ ) in our study had a high prevalence of vitamin D deficiency. It is worth mentioning that obesity has been well established as a risk factor for vitamin $\mathrm{D}$ deficiency. Several studies have demonstrated a close association between vitamin $\mathrm{D}$ deficiency and obesity among the Asian and Arab adult population [48]. Data from the World Health Organization (WHO) reveal that the UAE currently ranks fifth in the world in obesity, at a prevalence rate of 36\% (33\% for males and 39\% for females) [49].

The rapid socioeconomic transition in MENA countries has resulted in increased urbanization and drastic lifestyle changes and has also manifested in sedentary and unhealthy dietary practices. These factors combined with the growing fast-food industry has significantly impacted the prevalence of obesity among this population. Vitamin D deficiency and the rapid increase in the prevalence of obesity are both considered important public health issues contributing to morbidity and mortality in the UAE [50].

A series of evidence support the fact that obesity might be driving low serum $25(\mathrm{OH}) \mathrm{D}$ concentrations due to decreased bioavailability of vitamin $\mathrm{D}$ through sequestration within body fat and volumetric dilution [36,42]. It has been proposed that dietary calcium and vitamin D status might play a role in weight and fat regulation [51]. According to this hypothesis, lower calcium or vitamin D results in increased parathyroid hormone (PTH), which in turn decreases $25(\mathrm{OH}) \mathrm{D}$ and increases intracellular calcium into adipocytes, consequently inhibiting lipolysis and stimulating lipogenesis [52]. Furthermore, there are profound indications for an association between vitamin D levels and obesity, and that serum level of 25(OH)D are reduced in obese subjects in adults [53].

The data we analyzed highlighted that length of stay of greater than 5 years in the UAE was a strong predictor of vitamin D deficiency among female immigrants. This parameter is often used as an indicator of adjustment to a new culture acculturation. The relation between acculturation and immigrants' health is quite complex given the diversity of cultures and how temporal adaptation might affect health outcomes by embracing new habits that could act as risk factors for diseases, such asreduced physical activity and obesity [54]. A cross-sectional study in Canada that examined the prevalence of vitamin D deficiency among first generation immigrants $(n=11,579)$ concluded that the length of time lived in Canada, lifestyle, and ethnicity were important correlates. Overall, immigrants had significantly lower levels of $25(\mathrm{OH}) \mathrm{D}$ compared to native-born Canadians with Arabs and Southeast Asians in comparison to other white ethnic groups having the highest levels of vitamin D deficiency [55].

Immigration studies exploring the impact of acculturation on vitamin D status have demonstrated a significant positive correlation with the length of stay and serum $25(\mathrm{OH}) \mathrm{D}$ among immigrants in Canada [56]. This was in contrast with our findings and could be explained by the fact that integration into a new modernized life in the UAE with a thriving fast-food industry and more sedentary life could be the major culprit for the negative aspect of acculturation [55]. Importantly, food fortification with vitamin D in the UAE, unlike Canada, is not strictly implemented and this might also explain the conflicting results we obtained $[10,27]$.

However, our results are in concordance with reported findings from numerous other studies which examined the relationship between culture and health in the context of acculturation on the health of Asian immigrants in the US, Australia, and Europe [55]. A recent review confirmed that vitamin D deficiency was at epidemic levels among South Asian immigrants living in Western countries mainly due to low dietary intake of vitamin $\mathrm{D}$, high obesity, avoidance of sun exposure, and having covered sartorial dress style either due to cultural or religious reasons $[38,57]$. Moreover, investigators concluded that being a female, living in an urbanized setting, and limiting physical activity in Southeast Asia were strongly correlated with a low vitamin D status. In addition, religious, behavioral practices, and nutritional dissimilarities between Muslims and non-Muslims contributed to the remarkable differences in vitamin D status among these two subgroups of the same population in Thailand, with non-Muslims having $10 \mathrm{nmol} / \mathrm{L}$ higher levels of 25(OH)D [56]. 
The effect of clothing preference on vitamin D status of females has been well described by other researchers [58].

Vitamin D deficiency is a global public health crisis to which immigrants are predominantly susceptible especially with sub-populations that have darker skin and who move to the Western regions that have high latitudes [59]. In general, however, the vitamin D status of northern African countries was similar to populations in the Middle East, most likely due to similar environmental and behavioral styles [9]. In comparison to other ethnicities, immigrants from the African descent who settled in temperate areas in the US and Europe had a higher prevalence of vitamin D deficiency [60,61]. Moreover, national surveys in Europe reported that approximately $40 \%$ of these sub-populations had $25(\mathrm{OH}) \mathrm{D}$ concentrations below the sufficiency cutoff [62]. This pattern had been ascribed to the reduced adaptability of their darker skin color for vitamin D photosynthesis in regions that are not as sunny as Africa. Concurrently, a remarkable prevalence of $82.1 \%$ for vitamin D deficiency was documented among African American in the US in comparison to a nationwide mean value of $41.9 \%$ [60]. Moreover, a decrease in $25(\mathrm{OH}) \mathrm{D}$ concentrations was consistently reported with more northern latitudes and the duration of time since moving from Africa [59]. In a large sample $(n=12,346)$ of native Emirati population, a high proportion $(84 \%)$ of native Emirati females had vitamin D deficiency $(<50 \mathrm{nmol} / \mathrm{L})$ [63]. The predisposing factors for the vitamin D deficiency were high BMI, central obesity, high blood pressure, high cholesterol, and impaired blood glucose levels [64].

\section{Strengths and Limitations}

This study is the first to examine the prevalence of vitamin D deficiency among an under-studied and vulnerable subpopulation of female migrants in the UAE. Low vitamin D status along with other biomarkers among this subpopulation could signify health deterioration and the need for action. Our findings have valuable global health implications regarding the physical wellbeing of foreign immigrants and could inform future studies aiming to respond to chronic and infectious diseases including COVID-19 [63]. Moreover, the data obtained was for immigrants from different countries and could present a unique understanding to the cultural diversity and its intricate relation to immigrants' health within the UAE.

Despite the strength of the study, there are several limitations that should be acknowledged. The cross-sectional nature of design does not confirm causation of vitamin $\mathrm{D}$ deficiency, and hence findings remain correlational. Serum 25(OH)D concentrations are frequently used as clinical indicators for the assessment of vitamin D status, which is determined by sun exposure, dietary intake, and supplementation. In this research, such data was not available for analysis. However, the impact of seasonal variation in this study was minimal since the research was conducted in the summer, during which the contribution to vitamin D status by sun exposure is often restricted, since residents of the UAE avoid the sun and heat during this very hot season and spend their time indoor in cool air-conditioned settings [27,51]. We did not collect information on dietary habits, and/or supplement use, Fitzpatrick skin type, or tanning/outdoor habits. Vitamin D status is affected by diseases pertaining to impaired digestion and malabsorption like Crohn's and Celiac diseases; we did not collect this data in our study.

Examining differences in dietary habits, as well as behavioural practices towards sun exposure among the different subpopulations of female immigrants, are worth further investigation. The attitude and practices of the participants towards sun exposure were not explored but might have deterred them from securing an adequate vitamin D status. Whiter skin complexion had been associated with beauty, attractiveness, higher socio-economic advantages, and prestige among females from some populations, particularly in South Asia and Africa [65-68]. Lastly, genetic factors are also an important element to consider in such research owing to the contribution of genetic variants within vitamin D metabolism to the vitamin D status [68]. 


\section{Conclusions}

In conclusion, vitamin D deficiency is highly prevalent among female immigrant workers in the UAE. A prevention strategy including Vitamin D supplementation and educating this vulnerable subpopulation is urgently needed. Currently, the vitamin D recommendations for the UAE do not contain any specific guidelines for the immigrant subpopulations. Until food fortification with vitamin D becomes effective in the UAE, sun exposure and the use of supplements remain the most significant determinants of vitamin D status for the UAE population. Our study might have important connotations for introducing culturally acceptable approaches of increasing skin exposure to the sun and a subpopulation specific vitamin D dietary intake.

Author Contributions: S.M.S.: conceptualization, project administration, data analysis and interpretation, writing of original draft. F.A.A.: writing of original draft and interpretation of results. A.R.: formal analysis. N.S.: writing of methodology. R.A.: funding acquisition. W.B.G., L.A.A. and J.A.: reviewing and editing. All other authors contributed to reviewing final version. All authors have read and agreed to the published version of the manuscript.

Funding: This study was supported by a faculty grant number (NP09-30) from the College of Medicine and Health Sciences, UAE University, to S.K. The faculty grant for the project is entitled "Chronic Diseases Prevention in Immigrants: putting CVD risk factors on surveillance screen".

Institutional Review Board Statement: The study was conducted according to the guidelines of the Declaration of Helsinki and was approved by the Institutional Review Board (or Ethics Committee) of UAEU, Al Ain, UAE (AAMDHREC 10/21).

Informed Consent Statement: Informed consent was obtained from all subjects involved in the study.

Data Availability Statement: The data presented in this study are available on request from the corresponding author.

Acknowledgments: We thank the participants of the study for their willingness to participate and support research. We acknowledge the assistance of the health care workers; without their assistance this study would not have been possible.

Conflicts of Interest: William B. Grant receives funding from Bio-Tech Pharmacal, Inc. (Fayetteville, AR, USA). All other authors declare no conflict of interest.

\section{References}

1. $\quad$ Lips, P.; de Jongh, R.T.; Van Schoor, N.M. Trends in Vitamin D Status Around the World. JBMR Plus 2020, 12, e10585. [CrossRef] [PubMed]

2. Saraf, R.; Morton, S.M.B.; Camargo, C.A.; Grant, C.C. Global summary of maternal and newborn vitamin D status-A systematic review. Matern. Child Nutr. 2016, 12, 647-668. [CrossRef] [PubMed]

3. Bi, W.G.; Nuyt, A.M.; Weiler, H.; Leduc, L.; Santamaria, C.; Wei, S.Q. Association between vitamin D supplementation during pregnancy and offspring growth, morbidity, and mortality: A systematic review and meta-analysis. JAMA Pediatr. 2018, 7, 635-645. [CrossRef] [PubMed]

4. Holick, M.F.; Binkley, N.C.; Bischoff-Ferrari, H.A.; Gordon, C.M.; Hanley, D.A.; Heaney, R.P.; Murad, M.H.; Weaver, C.M. Evaluation, treatment, and prevention of vitamin D deficiency: An Endocrine Society clinical practice guideline. J. Clin. Endocrinol. Metab. 2011, 96, 1911-1930. [CrossRef] [PubMed]

5. Oristrell, J.; Oliva, J.C.; Casad, E.; Subirana, I.; Dominguez, D.; Toloba, A.; Balado, A.; Grau, M.J. Vitamin D supplementation and COVID-19 risk: A population-based, cohort study. J. Endocrinol. Investig. 2021, 45, 167-179. [CrossRef]

6. Dissanayake, H.A.; de Silva, N.L.; Sumanatilleke, M.; de Silva, S.D.N.; Gamage, K.K.K.; Dematapitiya, C.; Kuruppu, D.C.; Ranasimghe, P.; Sumanathan, S.; Katulanda, P.J. Prognostic and therapeutic role of vitamin D in COVID-19: Systematic review and meta-analysis. J. Clin. Endocrinol. Metab. 2021, 20, dgab892. [CrossRef] [PubMed]

7. Rejnmark, L.; Bislev, L.S.; Cashman, K.D.; Eirlksdottir, G.; Gaksch, M.; Grubler, M.; Grimnes, G.; Gudnason, V.; Lips, P.; Pilz, S.; et al. Non-skeletal healtheffects of vitamin D supplementation: A systematic review on finding from meta-analyses summarizing trial data. PLoS ONE 2017, 12, e0180512. [CrossRef]

8. Pludowski, P.; Holick, M.F.; Grant, W.B.; Konstantynowicz, J.; Mascarenhas, M.R.; Haq, A.; Povoroznyuk, V.; Balatska, N.; Barbosa, A.P.; Karonova, T.; et al. Vitamin D supplementation guidelines. J. Steroid Biochem. Mol. Biol. 2018, 175, 125-135. [CrossRef]

9. Chakhtoura, M.; Rahme, M.; Chamoun, N.; Fuleihan, G.E. Vitamin D in the Middle East, and North Africa. Bone Rep. 2018, 8, 135-146. [CrossRef] 
10. Grant, W.B.; Fakhoury, H.M.A.; Karras, S.N.; Al Anouti, F.; Bhattoa, H.P. Variations in 25-Hydroxyvitamin D in countries from the Middle East and Europe: The Roles of UVB Exposure and Diet. Nutrients 2019, 11, 2065. [CrossRef]

11. Welch, T.R.; Bergstrom, W.H.; Tsang, R.C. Vitamin D-deficient rickets: The re-emergence of a once conquered disease. J. Pediatr. 2000, 137, 143-145. [CrossRef] [PubMed]

12. Yared, M.N.; Chemali, R.; Yaacoub, N.; Halaby, G. Hypovitaminosis D in a sunny country: Relation to lifestyle and bone markers. J. Bone Miner. Res. 2000, 15, 1856-1862. [CrossRef]

13. Sedrani, K.M.; Elidrissy, A.W.T.H.; El-Arabi, K.M. Sunlight and vitamin D status in normal Saudi subjects. Am. J. Clin. Nutr. 1983, 38, 129-132. [CrossRef]

14. Hobbs, R.D.; Habib, Z.; Alromaihi, D.; Ldi, L.; Parikh, N.; Blocki, F.; Rao, D.S. Severe vitamin D deficiency in Arab-American women living in Dearborn, Michigan. Endocr. Pract. 2009, 15, 35-40. [CrossRef] [PubMed]

15. Muhairi, S.J.; Mehairi, A.E.; Khouri, A.A.; Naqbi, M.; Maskari, F.; Al Kaabi, J.; Al Dhaheri, A.; Naglekerke, N.; Shah, S. Vitamin D deficiency among healthy adolescents in Al Ain, United Arab Emirates. BMC Public Health 2013, 13, 33. [CrossRef] [PubMed]

16. United Arab Emirates Ministry of Economy. Preliminary Results of Population, Housing, and Establishment Census 2005, United Arab Emirates 2006. Available online: http:/ / www.cscc.unc.edu/uaee/public/UNLICOMMUAE2005CensusResults07282008. pdf (accessed on 10 June 2020).

17. Yousef, S.; Elliott, J.; Manuel, D.; Colman, I.; Papadimitropoulos, M.; Hossain, A.; Leclair, N.; Well, G.A. Study protocol: Worldwide comparison of vitamin D status of immigrants from different ethnic origins and native-born populations-a systematic review and meta-analysis. Syst. Rev. 2019, 8, 211. [CrossRef] [PubMed]

18. Shah, S.M.; Ali, R.; Loney, T.; Aziz, F.; ElBarazi, I.; Al Dhaheri, S.; Farooqi, M.H.; Blair, I. Prevalence of diabetes among migrant women and duration of residence in the United Arab Emirates: A cross sectional study. PLoS ONE 2017, 12, e0169949. [CrossRef] [PubMed]

19. World Health Organization. The WHO STEPwise Approach to Noncommunicable Disease Risk Factor Surveillance. Available online: https://www.who.int/ncds/surveillance/steps/STEPS_Manual.pdf (accessed on 16 May 2020).

20. Herrick, K.A.; Storandt, R.J.; Afful, J.; Pfeiffer, C.M.; Schleicher, R.L.; Gahche, J.J.; Potischman, N. Vitamin D status in the United States 2011-2014. Am. J. Clin. Nutr. 2019, 110, 150-157. [CrossRef]

21. Pottie, K.; Greenaway, C.; Feightner, J.; Welch, V.; Swinkels, H.; Rashid, M.; Narasiah, L.; Kirmayer, L.J.; Ueffing, E.; MacDonald, N.E.; et al. Evidence-based clinical guidelines for immigrants and refugees. CMAJ 2011, 183, E824-E925. [CrossRef]

22. World Health Organization. Obesity: Preventing and Managing the Global Epidemic: Report of a WHO Consultation; World Health Organization: Geneva, Switzerland, 2000.

23. 1999 World Health Organization-International Society of Hypertension Guidelines for the Management of Hypertension. Guidelines Subcommittee. J. Hypertens. 1999, 17, 151-183.

24. International Physical Activity Questionnaire (IPAQ). Guidelines for Data Processing and Analysis of the International Physical Activity Questionnaire (IPAQ)-Short and Long Forms. 2005. Available online: http:/ /www.ipaq.ki.se/scoring.pdf (accessed on 16 May 2020).

25. Haskell, W.L.; Lee, I.M.; Pate, R.R.; Powell, K.E.; Blair, S.N.; Franklin, B.A.; Macera, C.A.; Heath, G.W.; Thompson, P.D.; Bauman, A. Physical activity and public health: Updated recommendation for adults from the American College of Sports Medicine and the American Heart Association. Med. Sci. Sports Exerc. 2007, 39, 1423-1434. [CrossRef] [PubMed]

26. Haq, A.; Svobodova, J.; Imran, S.; Stanford, C.; Razzaque, M.S. Vitamin D deficiency: A single center analysis of patients from 136 countries. J. Steroid Biochem. Mol. Biol. 2016, 164, 209-213. [CrossRef] [PubMed]

27. Schleicher, R.L.; Sternberg, M.R.; Looker, A.C.; Yetley, E.A.; Lacher, D.A.; Sempos, C.T.; Taylor, C.L.; Durazo-Arvizu, R.A.; Maw, K.L.; Chaudhary-Webb, M.; et al. National estimates of serum $25(\mathrm{OH}) \mathrm{D}$ and metabolite concentrations measured by liquid chromatography-Tandem, mass spectrometry in the US population during 2007-2010. J. Nutr. 2016, 146, 1051-1061. [CrossRef] [PubMed]

28. Sarafin, K.; Durazo-Arvizu, R.; Tian, L.; Phinney, K.W.; Tai, S.; Camara, J.E.; Merkel, J.; Green, E.; Sempos, C.T.; Brooks, S.P. Standardizing 25-hydoxyvitamin D values from the Canadian Health Measures Survey. Am. J. Clin. Nutr. 2015, 102, 1044-1050. [CrossRef] [PubMed]

29. Horton-French, K.; Dunlop, E.; Lucas, R.M.; Pereira, G.; Black, L.J. Prevalence and predictors of vitamin D deficiency in a nationally representative sample of Australian adolescents and young adults. Eur. J. Clin. Nutr. 2021, 75, 1627-1636. [CrossRef]

30. Lips, P.; Cashman, K.D.; Lamberg-Allardt, C.; Bischoff-Ferrari, H.A.; Obermayer-Pietsch, B.R.; Bianchi, M.; Stepan, J.; El-Hajj Fuleihan, G.; Bouillon, R. Current vitamin D status in European and Middle East countries and strategies to prevent vitamin D deficiency: A position statement of the European Calcified Tissue Society. Eur. J. Endocrinol. 2019, 180, 23-54. [CrossRef]

31. Mogire, R.M.; Mutua, A.; Kimita, W.; Kamau, A.; Bejon, P.; Pettifor, J.M.; Adeyemo, A.; Williams, T.N.; Atkinson, S.H. Prevalence of vitamin D deficiency in Africa: A systematic review and meta-analysis. Lancet Glob. Health 2020, 8, e134-42. [CrossRef]

32. Clemens, T.L.; Henderson, S.L.; Adams, J.S.; Holick, M.F. Increased skin pigment reduces the capacity skin to synthesise vitamin D3. Lancet 1982, 319, 4-6. [CrossRef]

33. Nesby-O'Dell, S.; Scanlon, K.S.; Cogswell, M.E.; Gillespie, C.; Hollis, B.W.; Looker, A.C.; Allen, C.; Doughertly, C.; Gunter, E.W.; Bowman, B.A. Hypovitaminosis D prevalence and determinants among White women of reproductive age: Third National and Nutrition Examination Survey 1988-1994. Am. J. Clin. Nutr. 2002, 76, 187-192. [CrossRef]

34. Yetley, E.A. Assessing the Vitamin D status of the US population. Am. J. Clin. Nutr. 2008, 88, 558S-564S. [CrossRef] 
35. Jiang, Z.; Pu, R.; Li, N.; Chen, C.; Li, J.; Dai, W.; Wang, Y.; Hu, J.; Zhu, D.; Yu, Q.; et al. High prevalence of vitamin D deficiency in Asia: A systematic review and meta-analysis. Crit. Rev. Food Sci. Nutr. 2021, 16, 1-10. [CrossRef] [PubMed]

36. Kambo, P.; Dwivedi, S.; Toteja, G.S. Prevalence of hypovitaminosis D in India \& wayfoward. Indian J. Med. Res. 2018, 148, 548-556. [CrossRef]

37. Darling, A.L. Vitamin D deficiency in western dwelling South Asian populations: An unrecognized epidemic. Proc. Nutr. Soc. 2020, 79, 259-271. [CrossRef] [PubMed]

38. Brock, K.; Huang, W.Y.; Fraser, D.R.; Ke, L.; Tseng, M.; Stolzenberg-Solomon, R.; Peters, U.; Ahn, J.; Purdue, M.; Mason, R.S.; et al. Low vitamin D is associated with physical inactivity, obesity and low vitamin D intake in a large US sample of healthy middle-aged men and women. J. Steroid Biochem. Mol. Biol. 2010, 121, 462-466. [CrossRef] [PubMed]

39. Zumaraga, M.P.; Concepcion, M.A.; Duante, C.; Rodriguez, M. Next Generation Sequencing of Lifestyle and Nutrition related genetic polymorphisms reveals independent loci for low serum 25-hydroxyvitamin D levels among adult respondents of the 2013 Philippine National Nutrition Survey. J. Asean Fed. Endocr. Soc. 2021, 36, 56-63. [CrossRef] [PubMed]

40. Valentini, A.; Perrone, M.A.; Cianfarani, M.A.; Tarantino, U.; Massoud, R.; Merra, G.; Bernardini, S.; Morris, H.A.; Bertoli, A. Obesity, vitamin D status and physical activity: 1,25(OH)2D as a potential marker of vitamin D deficiency in obese subjects. Panminerva Med. 2020, 62, 83-92. [CrossRef]

41. De Oliveira, L.F.; De Azevedo, L.G.; da Mota Santana, J.; de Sales, L.P.C.; Pereira Santos, M. Obesity and overweight decreases the effect of 25(OH) D supplementation in adults: Systematic review and meta-analysis of randomized controlled trials. Rev. Endocr. Metab. Disord. 2020, 21, 61. [CrossRef]

42. Holick, M.F. Biological Effects of Sunlight, Ultraviolet Radiation, Visible Light, Infrared Radiation and Vitamin D for Health Anticancer Res. 2016, 36, 1345-1356.

43. Pietiläinen, K.H.; Kaprio, J.; Borg, P.; Plasqui, G.; Yki-Järvinen, H.; Kujala, U.M.; Rose, R.J.; Westerterp, K.R.; Rissanen, A. Physical inactivity and obesity: A vicious circle. Obesity 2008, 16, 409-414. [CrossRef]

44. Scott, D.; Blizzard, L.; Fell, J.; Ding, C.; Winzenberg, T.; Jones, G. A prospective study of the associations between 25-hydroxyvitamin D, sarcopenia progression and physical activity in older adults. Clin. Endocrinol. 2010, 73, 581-587. [CrossRef]

45. Pang, Y.; Kim, O.; Choi, J.A.; Jung, H.; Kim, J.; Lee, H.; Lee, H. Vitamin D deficiency and associated factors in south Korean childbearing women: A cross-sectional study. BMC Nurs. 2021, 20, 218. [CrossRef] [PubMed]

46. Al-Othman, A.; Al-Musharaf, S.; Al-Daghri, N.M.; Krishnaswamy, S.; Yusuf, D.S.; Alkharfy, K.M.; Al-Saleh, Y.; Al-Attas, O.S.; Alokail, M.S.; Moharram, O.; et al. Effect of physical activity and sun exposure on vitamin D status of Saudi children and adolescents. BMC Pediatr. 2012, 12, 92.

47. Liu, X.; Baylin, A.; Levy, P.D. Vitamin D deficiency and insufficiency among US adults: Prevalence, predictors and clinical implications. Br. J. Nutr. 2018, 119, 928-936. [CrossRef] [PubMed]

48. World Health Organization. Obesity and Overweight. 2021. Available online: https://www.who.int/news-room/fact-sheets/ detail/obesity-and-overweight (accessed on 10 June 2021).

49. Haq, A.; Wimalawansa, S.J.; Pludowski, P.; Anouti, F.A. Clinical practice guidelines for vitamin D in the United Arab Emirates. J. Steroid Biochem. Mol. Biol. 2018, 175, 4-11. [CrossRef]

50. Zemel, M.B.; Shi, H.; Greer, B.; Dirienzo, D.; Zemel, P.C. Regulation of adiposity by dietary calcium. FASEB J. 2000, 14, 1132-1138 [CrossRef]

51. Chang, E.; Kim, Y. Vitamin D decreases adipocyte lipid storage and increases NAD-SIRT1 pathway in 3T3-L1 adipocytes. Nutrition 2016, 32, 702-708. [CrossRef]

52. De Pergola, G.; Martino, T.; Zupo, R.; Caccavo, D.; Pecorella, C.; Paradiso, S.; Silvestris, F.; Triggiani, V. 25 Hydroxyvitamin D Levels are Negatively and Independently Associated with Fat Mass in a Cohort of Healthy Overweight and Obese Subjects. Endocr. Metab. Immune Disord. Drug Targets 2019, 19, 838-844. [CrossRef]

53. Salant, T.; Lauderdale, D.S. Measuring culture: A critical review of acculturation and health in Asian immigrant populations. Soc. Sci. Med. 2003, 57, 71-90. [CrossRef]

54. Yousef, S.; Manuel, D.; Colman, I.; Papadimitropoulos, M.; Hossain, A.; Faris, M.; Wells, G.A. Vitamin D Status among FirstGeneration Immigrants from Different Ethnic Groups and Origins: An Observational Study Using the Canadian Health Measures Survey. Nutrients 2021, 13, 2702. [CrossRef]

55. Sanou, D.; O’Reilly, E.; Ngnie-Teta, I.; Batal, M.; Mondain, N.; Andrew, C.; Newbold, B.K.; Bourgeault, I.L. Acculturation and nutritional health of immigrants in Canada: A scoping review. J. Immigant Minority Health 2014, 16, 24-34. [CrossRef]

56. Buyukuslu, N.; Esin, K.; Hizli, H.; Sunal, N.; Yigit, P.; Garipagaoglu, M. Clothing preference affects vitamin D status of young women. Nutr. Res. 2014, 34, 688-693. [CrossRef] [PubMed]

57. Chailurkit, L.O.; Aekplakorn, W.; Ongphiphadhanakul, B. Regional variation and determinants of vitamin D status in sunshineabundant Thailand. BMC Public Health 2011, 11, 853. [CrossRef] [PubMed]

58. Martin, C.A.; Gowda, U.; Renzaho, A.M. The prevalence of vitamin D deficiency among dark-skinned populations according to their stage of migration and region of birth: A meta-analysis. Nutrition 2016, 32, 21-32. [CrossRef] [PubMed]

59. Harris, S.S. Vitamin D and African Americans. J. Nutr. 2006, 136, 1126-1129. [CrossRef] [PubMed]

60. Arabi, A. El Rassi, R.; El-Hajj, F.G. Hypovitaminosis D in developing countries-prevalence, risk factors and outcomes. Nat. Rev. Endocrinol. 2010, 6, 550-561. [CrossRef] [PubMed] 
61. Durazo-Arvizu, R.A.; Camacho, P.; Bovet, P.; Forrester, T.; Lambert, E.V.; Plange-Rhule, J.; Hoofnagle, A.N.; Aloia, J.; Tayo, B.; Dugas, L.R.; et al. 25-Hydroxyvitamin D in African-origin populations at varying latitudes challenges the construct of a physiologic norm. Am. J. Clin. Nutr. 2014, 100, 908-914. [CrossRef] [PubMed]

62. AlZarooni, A.A.R.; AlMarzouqi, F.I.; AlDramaki, S.H.; Prinsloo, E.A.M.; Nagelkerke, N. Prevalence of vitamin D deficiency and associated comorbidities among Abu Dhabi Emirates population. BMC Res. Notes 2019, 12, 503. [CrossRef]

63. Alrayyes, S.F.; Alrayyes, S.F.; Farooq, U.D. Skin-lightening patterns among female students: A cross-sectional study in Saudi Arabia. Int. J. Women's Dermatol. 2019, 5, 246-250. [CrossRef] [PubMed]

64. Janzi, S.; Padilla, E.C.; Najafi KRamne, S.; Ahlqvist, E.; Borne, Y.; Sonestedt, E. Single Nucleotide Polymorphisms in close proximity to the fibroblast growth factor 11 (FG21) Gene Found to be associated with sugar intake in a Swedish population. Nutrients 2021, 13, 3954. [CrossRef] [PubMed]

65. Coetzee, V.; Faerber, S.J.; Greeff, J.M.; Lefevre, C.E.; Re, D.E.; Perrett, D.I. African Perceptions of Female Attractiveness. PLoS ONE 2012, 7, e48116. [CrossRef] [PubMed]

66. Shroff, H.; Diedrichs, P.C.; Craddock, N. Skin Color, Cultural Capital, and Beauty Products: An Investigation of the Use of Skin Fairness Products in Mumbai, India. Front. Public Health 2018, 5, 365. [CrossRef] [PubMed]

67. Li, E.P.H.; Min, H.J.; Belk, R.W.; Kimura, J.; Bahl, S. Skin Lightening and Beauty in Four Asian Cultures. Adv. Consum. Res. 2008, 35, 444-449.

68. Carlberg, C. Nutrigenomics of vitamin D. Nutrients 2019, 11, 676. [CrossRef] [PubMed] 